\section{P2-87 EFFECTS OF NEIGHBOURHOOD FEATURES ON OBESITY: SAÚDE EM BEAGÁ STUDY, BELO HORIZONTE, BRAZIL, 2008-2009}

\author{
doi:10.1136/jech.2011.142976i.22
}

\begin{abstract}
${ }^{1,2} \mathrm{~A}$ Friche, ${ }^{*}{ }^{1,2} \mathrm{~A}$ Ferreira, ${ }^{3} \mathrm{~A}$ Diez-Roux, ${ }^{1,2} \mathrm{C}$ César, ${ }^{1,2} \mathrm{~F}$ Proietti, ${ }^{1} \mathrm{~W}$ Caiaffa. ${ }^{1}$ Graduate Program of Public Health, School of Medicina, Federal University of Minas Gerais, Belo Horizonte, Minas Gerias, Brazil; ${ }^{2}$ Observatory for Urban Health, Federal University of Minas Gerais, Belo Horizonte, Minas Gerias, Brazil; ${ }^{3}$ Center for Social Epidemiology and Population Health/School of Public Health/University of Michigan, Ann Arbor, Michigan, USA
\end{abstract}

Introduction The prevalence of obesity seems to be increasing in most parts of the world. Some studies have examined the association between the environment and obesity.

Objective To address how neighbourhood factors affect obesity by examining individual, household and neighbourhood-level characteristics.

Methods Data from a multistage (census tracts, households, and residents) household survey (2008-2009) conducted in Belo Horizonte City by the Observatory for Urban Health. Obesity was defined as a body mass index of $30 \mathrm{~kg} / \mathrm{m}^{2}$ or more. The individual and household level included demographic and socioeconomic characteristics. To assess the neighbourhood features we used nine scales using individual responses to represent different dimensions of neighbourhood: Public Services, Aesthetic Quality, Walking Environment, Violence, Social Cohesion, Activities with Neighbours, Neighbourhood Physical Disorders, Neighbourhood Social Disorders and Neighbourhood Problems. Multivariate multilevel models were fitted for each scale considering the sampling design.

Results Of the 4048 adults, $54.1 \%$ were female; the mean age was 41.2 (CI 40.5 to 41.9 ) years; the obesity prevalence was $18.2 \%$. For all models obesity was associated with higher age and female gender. After adjusted for individual and household characteristics none scale remained associated with obesity. Although the sampling size comprised to select heterogeneous areas the distribution of obesity was homogenous among the studied area probably masking the contextual effects on obesity.

Conclusion Contrary to expectations, the hypothesis of neighbourhood effects on obesity was not confirmed in this work. We suggest future studies that use other environment measures to provide evidences helping to control the obesity epidemic in the Brazilian population.

\section{P2-88 MARITAL STATUS IS A RISK FACTOR FOR OVERWEIGHT AND OBESITY, INDEPENDENTLY OF DEMOGRAPHIC AND SOCIOECONOMIC CHARACTERISTICS: A POPULATION- BASED STUDY}

\section{doi:10.1136/jech.2011.142976i.23}

${ }^{1,2}$ S C Fuchs, ${ }^{* 1}$ B Soldateli, ${ }^{1,2}$ L B Moreira, ${ }^{2}$ F D Fuchs. ${ }^{1}$ Postgraduate Studies Program in Epidemiology, Universidade Federal do Rio Grande do Sul, Porto Alegre, Rio Grande do Sul, Brazil; '2Division of Cardiology, Hospital de Clinicas de Porto Alegre, Porto Alegre, Rio Grande do Sul, Brazil

Introduction Marital status has been associated with lower quality of life and chronic conditions.

Objective To evaluate the independent association of marital status with overweight and obesity in a population-based sample from southern Brazil.

Methods A cross-sectional study was conducted in a populationbased sampling of 1858 adults aged 18-90 years. Participants were interviewed at home, weight and height were measured to calculate body mass index (BMI). Obesity was define as
$\mathrm{BMI} \geq 30 \mathrm{~kg} / \mathrm{m}^{2}$; overweight as $\mathrm{BMI}=25-29 \mathrm{~kg} / \mathrm{m}^{2}$, and marital status as married, divorced or widow, and single. Prevalence rates (95\% CI) and RRs (95\% CI) were calculated and multivariate analysis in the Cox Regression Model, using the Complex Samples module of SPSS, to adjust for age, education, gender, and sampling design effect.

Results The sample included $58 \%$ of women, aged $48.9( \pm 19.1)$ years, and with on average of $9.4( \pm 4.7)$ years of formal education. Prevalence of obesity was higher among women $(23.5 \%)$ than men $(17.5 \%)(p=0.006)$, but not overweight prevalence ( $30.4 \%$ vs $35.5 \%$, respectively, $\mathrm{p}=0.2)$. There was of obesity and overweight with age. In multivariate analysis, obesity remained independently associated with female gender $(p=0.03),<12$ years at school $(p=0.02)$, age $>29$ years-old $(p<0.001)$, and being marriaged $[(R R=14.4(1.1-1.8)$; $p=0.02]$, in comparison to be single. Overweight was also independently associated with age $(p<0.001)$, education $(p=0.02)$ and marital status $(p<0.001)$ for being marriaged $[(R R=1.7(1.3-2.3)]$, but being separated or divorced reached a borderline significance $[\mathrm{RR}=1.3(1.0-1.7)]$

Conclusion Married men and women have higher overweight and obesity prevalence independently of socioeconomic characteristics.

\section{P2-89 QUALITY OF LIFE IS ASSOCIATED WITH ACCUMULATED RISK FACTORS FOR CARDIOVASCULAR DISEASE: A POPULATION-BASED STUDY}

doi:10.1136/jech.2011.142976i.24

${ }^{1,2} \mathrm{~S}$ C Fuchs, ${ }^{*}{ }^{1,2} \mathrm{~L}$ B Moreira, ${ }^{1} \mathrm{D} \mathrm{J}$ Trevisol, ${ }^{1,2} \mathrm{M}$ Gus, ${ }^{2} \mathrm{M}$ Wiehe, ${ }^{1,2} \mathrm{~F}$ D Fuchs. ${ }^{1}$ Postgraduate Studies Program in Cardiology, Universidade Federal do Rio Grande do Sul, Porto Alegre, Rio Grande do Sul, Brazil; ${ }^{2}$ Division of Cardiology, Hospital de Clinicas de Porto Alegre, Porto Alegre, Rio Grande do Sul, Brazil

Introduction Health-related quality of life ( $\mathrm{QoL})$ is largely affected by cardiovascular disease, but it not known the effect of accumulated risk factors

Objective To evaluate the association between cardiovascular risk factors and health-related $\mathrm{QoL}$ in a population-based sampling from southern Brazil.

Methods This population-based cross-sectional study included 1858 adults, aged 18-90 years. Standardised interviews and measurements detected obesity (BMI $\geq 30 \mathrm{~kg} / \mathrm{m}^{2}$ ); alcoholic beverage consumption (grams of ethanol/day); smoking, and physical inactivity ( $<150 \mathrm{~min} /$ day). Hypertension was identified by blood pressure $\geq 140 / 90 \mathrm{~mm} \mathrm{Hg}$ or lowering drugs. OoL was detected by Short-Form Health Survey (SF-12) for Physical Component Summary (PCS) and Mental Component Summary (MCS). General Linear Model, of the SPSS-Complex Samples module, was used for multivariate analysis, controlling for design effect and confounding factors.

Results Participants had 48.9 \pm 19.1 years-old, 9.4 \pm 4.7 years at school, and $58 \%$ were women. Low PCS scores were determined for low education level, females, age $\geq 65$ year, but only the last two risk factors were associated with low MCS score. Lower PCS were detected for obesity (46.9 vs 49.5; $\mathrm{p}<0.001$ ), hypertension (47.6 vs 49.9; $\mathrm{p}<0.001$ ), diabetes (45.6 vs 49.2; $\mathrm{p}<0.001$ ), and physically inactive (46.7 vs 49.7; $\mathrm{p}<0.001$ ), independently of confounding factors, as well as for MCS for non-smoking participants (49.4) (vs 51.9 ex-smokers and 51.2 smokers; $\mathrm{p}=0.003$ ), physically inactive ( 49.9 vs $51.4 ; p=0.008$ ), hypertensive ( 49.9 vs $51.9 ; p=0.007$ ), and diabetics (48.6 vs $51.2 ; p=0.008$ ). There was a curve-response between the number of risk factors and PCS $(p<0.001)$ and MCS scores $(p<0.001)$.

Conclusion Individuals who accumulated risk factors have poorer health-related QoL. 